\title{
Product Experience Design in Service Economy
}

\author{
Xin Liu \\ School of Industrial Design and Ceramic Art, Foshan University, Foshan Guangdong, 528000, China
}

Keywords: Service economy, Product, Experience design.

\begin{abstract}
In product experience design, much stress is laid on users' emotional experience and inner needs, with a view to fully developing the profitability of product, and giving full play to the application value of product. An experience system is helpful for product designer to expand the dimension of thinking, and combine traditional product design with service system, to ensure better development of product design and production mode design.
\end{abstract}

\section{Introduction}

Under the influence of experience economy, experience design emerged, which is helpful to give full play to the essence of the idea of economic strategy. In experience economy, much stress is laid on users' satisfaction, and various measures are taken to meet users' spiritual needs, so as to constantly increase the additional value of products. Emotional factors are important to some kinds of design, which requires to lay stress on users' emotional needs to reflect users' spirit and emotion. This paper is intended to discuss product experience design under service economy, to provide a theoretical basis for related researches.

\section{Trend of Experience-oriented Product under Service Economy}

In modern times, fashion does not dominate people consumption pattern any more. Instead, various different economic activities gradually awaken people's self-consumption desire, address people's basic living needs, and promote people to further develop. In agricultural economy and industrial economy, design is usually need-oriented, and in the age of service economy, experience design is integrated into modern design. So far, social division of labor has been further deepened, and service-orientation of the economic society has been realized via service economy. Due to the limitations of traditional scopes of service, service economy emerges in both the service industry and the process of the manufacturing industry and the tertiary industry integrating and developing, so that new commercial activities and new industries constantly emerge. Many enterprises start to transform themselves actively, to center on consumers, provide good services, and create a better experience for consumers. Under the influence of service economy, the largest profit point of enterprises rests in the contents as mentioned above.

The economic crisis helped Chinese design enterprises clearly learn about the prosperity and saturation of manufacturing in China. Taking this opportunity, many enterprises started to transform to realize service-orientation. Presently, the value orientation in consumption mainly covers instrumental value and ultimate value. Both utility value and unique experience are needed by consumers to resonate with their own psychological needs. Thus, the expressional language of design is not for simple evolution and transformation of visual signs any longer, but needs careful study on users' emotion and visual psychological system. Designers are required to have a clear understanding of users' emotional needs and psychical elements, and explore new profit model for enterprises, so as to largely expand the dimensions of product design.

Consumers in modern times are being in the later period of the industrial society. Comparing with traditional users, their preference of products and characteristics have largely changed. For example, the constant evolution of communication products reflects the process of product experience design, and the close relationship between design and consumer market. The main contents of product 
experience design constitute an experience system, which include sensual experience, emotional experience, thinking experience, association experience, and behavior experience.

\section{Composition of Experience System}

Sensual experience covers visual sense, auditory sense, gustatory sense, and so on, and enables designers to attract users to enter an experience environment with straightforward design language. Designers cannot solve the man-machine relationship of products from the perspective of sensual experience. Instead, sensual experience is mainly for arousing consumers' emotional experience. Emotional experience is helpful to stimulate consumers' internal emotion to resonate in product cognition in some way. Thinking experience is for arousing consumers' interest in an innovative way, helping consumers to think and solve problems and get satisfaction in this process. Behavior experience refers to behaviors affecting others, which enhances participants' physical experience and defines concrete alternative methods. Association experience refers to giving extra experience to consumers, which is not only specific to users' direct needs, but also closely related to products' instrumentality. Designers create good extra experience and interests from the perspective of life of consumption, and consumers can have fun in products. Emotional experience is for realizing more smooth communication. Thinking experience can enter people's soul and brain, users can immerse themselves in experience, and designers can fully express thinking appeal and creativity in this process. Association experience is helpful to raise the commercial value of design cases, give more connotation and meaning to products, break through the frame of traditional design, and constantly innovate commercial mode.

There are various types of experience system available. Different products bring about different experiences to consumers, but such experiences essentially are a mixture, which can not only bring various experiences to users, but also provide various experience information to users. Users' needs vary, and product design and needs vary accordingly. Different experiences are interrelated to each other, and the interrelations are complicated. Experience design requires designers to control and take account of a lot of factors, and manipulate and utilize these factors in a sensitive way.

\section{Product Experience Design Method}

\section{Determination of Experience Theme}

Once the theme of product experience is determined, design activities about the theme can be carried out. In modern times, market competition becomes increasingly intense, and consumers' aesthetic standards also gradually rise. Thus, novel and appealing theme of experience design should be determined to give real experience and adequate information to consumers. For selection of theme, the market trend should be taken into account, to cover more targets as far as possible. Designers should have a clear understanding of consumers' habits and characteristics, and take account of geographical location and social environment to determine the ultimate theme. To enhance the theme, designers should lay stress on the function of use of products in design process, to meet consumers' usage requirements. If the production capacity permits, designers should meet consumers' experience needs as far as possible. For innovating experience environment, it is feasible to highlight some experience in the process of product design to impress consumers. In the process of theme determination, designers need to take account of various factors helping highlight the theme, so as to foil the theme.

\section{Differences of Created Products}

Besides that users' experience needs should be met, a product also should be distinguished from other products, so as to give a feeling of freshness to consumers and stimulate consumers to form a desire of purchase. This is because most people tend to have a consumption psychology for realizing individualization in modern times. If modeling coincides with the design idea, it is hard to stand out in intense competition to meet consumers' usage requirements. Only innovative and creative products 
can stand out and gain consumers' favor. This requires to reflect the differences in the links of modeling, design idea, production and marketing of products.

\section{Enhancement of Market Survey}

To address consumer needs better via product design experience, greater efforts should be made to enhance market survey, which requires to divide consumers carefully to determine market demands. Meanwhile, designers also should have a clear understanding of products of the competitors. Market demands usually have obvious characteristics, but market demands constantly change, which needs concrete investigation and study. For example, for designing a product, designers should learn about the market structure, have a clear understanding of the main targets of the product, and grasp the needs of the consumers by means of questionnaire survey, which is helpful to differentiate design objects. Meanwhile, designers should master competitors' product design information, and analyze competitors' product characteristics and differences, so as to create a better design experience. Designers need master the market situation via constant investigation and survey, so as to develop an initial concept of product. The market is always changing. As various factors constantly change, designers should try their best to break through the limitations of the internal environment of market, and predict the variation trend in the future, to realize advanced experience design of product.

\section{Enhancement of Participative Experience}

Product design is determined by experience environment. Consumers can get satisfied in the process of utilizing product. The design of experience environment should be carried out based on consideration of consumers' environment. The environment of every consumer is different to a certain extent, so that consumers can have different feelings of product experience. Only by fully understanding these factors, designers can accurately master users' usage requirements and psychological needs, to give good product experience to users. For example, some video enterprises, to show the healthy nature of product and the theme of environmentally-friendliness, have constructed factory with glass walls to make the whole production process visible to consumers, so as to dispel consumers' doubts, and help consumers have a good impression on the product and form a desire of purchase. Besides, consumers, entering such environment, can obtain intuitive experience and a sense of achievement, and have more confidence in the product by active participation.

\section{Commercialization of Experience Design Factors}

The powerful and successful enterprises in modern times usually lay stress on feeling strategy and emotional strategy, so that they always try best to enhance these experiences via commercial design. But it is difficult for traditional manufacturing to transform. Enterprise designers usually pay more attention to technical details. But they should pay more attention to consumers' usage experience. The following is an analysis of this based on the five factors of experience system.

Enterprises can increase the experience factors of product, to help interaction between consumers and product, and realize information perceptualization of product. The quality of some traditional products can be made full use of to amuse consumers. Enterprises can make product more attractive by highlighting some perceptual feature of product. For example, automobile manufacturing enterprises usually lay stress on model test to optimize the sound of door closing. Publishers usually make innovation in the aspect of tactile stimulation, and integrate new visual technology, to largely improve the cover and quality of books and magazines. By enhancing the perceptual features of product, users' impression and using experience can be constantly deepened. Thus, consumers can have a more complete and deeper impression, and their satisfaction can be improved.

Information technology is useful to produce more appealing products. But designers cannot rely solely on technical progress. Otherwise, they cannot provide consumers' with satisfactory services and products. Thus, it is necessary to design product experience throughout the product cycle. In the advertising process of enterprises, this is helpful to distinguish the brand image of enterprises. If the experience value is integrated into the brand image, consumers will have an obscure product experience in the link of marketing. Take the example of Nike company. The company manufactures 
products with high-quality materials, and also combines technical design with visual communication, so that it has the characteristics of multimedia in the process of branding strategy, and consumers can associate Nike with comfortable movement experience. PepsiCo also does well in this aspect. The company employs passionate giant stars to endorsing its products, so that consumers can obtain certain visual perception while getting satisfied with the products, and even imagine that they are in the scene as presented in the ad. This is the way that consumers' experience is expanded, and brand also forms certain service value accordingly.

Making product scarce is one of the approaches of innovating product experience and improving product' association value. Purchasers will obtain value satisfaction if they have bought a unique product, which exceeds the value of the product itself. For example, every pair of Nike Air Jordan bears a unique number, so that every pair becomes unique. The secondary market also can be developed to realize marketing at a higher price. The manufacturing of such products can be carried out in combination with the local market conditions. Thus, a new pricing model can be established, and it becomes realizable to market the products at higher prices, to achieve higher value of every single product.

\section{Conclusion}

Under the context of service economy, designers grasp design language of products and realize creative application thereof based on deep analysis of consumers and accurate determination of consumers' experience needs. Besides, they also realize experience innovation in the links of marketing and service in combination with various commercial models. To address individualized user needs, designers need analyze the market carefully, learn about users' psychological changes, emphasize the special requirements of local consumers, and always pay attention to consumers' cultural values. To conduct experience design under service economy, designers need give full play to their professional skills, and deeply understand psychological and economic knowledge, to improve their competitiveness.

\section{References}

[1] Huang Xin. Thinking on Development and Design of Tourism Products under the Experience Economy, Market Modernization, 2009, (17):136. 2017-08-02.

[2] Tan Chunxia, Gu Minyan. Innovative Design of Tourism Products of Historic Village-Zhuge Bagua Village under the Experience Economy, Resource Development \& Market, 2009, 25 (08): 767-768+681. 2017-08-02.

[3] Wu Wenzhi, Zhuang Zhimin. Design and Innovation of Tourism Products under the Experience Economy-Case Study of Experience-Oriented Development of Tourism Products of Historic Village, Tourism Tribune, 2003, (06): 66-70. 2017-08-02.

[4] Ma Liqin. Innovative Design of Ocean Tourism of Artificial Science and Technology and Products from the Perspective of Experience Economy, Journal of Business Economics, 2005, (06): 65-69. 2017-08-02. DOI : 10.14134/j.cnki.cn33-1336/f.2005.06.014

[5] Xu Lin, Bao Hongli. Construction of Tourist Experience Design Idea and Tourism Product System-Case Study of Xinzhou District of Wuhan Municipality, Enterprise Economy, 2007, (02): 91-93. [2017-08-02]. DOI : 10.13529/j.cnki.enterprise.economy.2007.02.030

[6] Wu Jinfeng. Distinction of Concepts of Tourist Attraction, Tourism Resource, Tourism Product and Tourism Experience, Economic Management, 2014, 36 (08): 126-136. [2017-08-02].

[7] Zhang Jin. Exploration and Analysis of Approach of Development and Design of Tourism Products of Minority Culture in the Age of Experience Economy, Journal of Guizhou Minzu University (Philosophy and Science Sciences), 2015, (01): 186-189. [2017-08-02]. 
[8] He Diaoxia. Study on Tourism Market Survey of College Students and Tourism Product Design under the Context of Experience Economy-Case Study of Wuxi Outang E-park, China Economist, 2015, (11): 187-189. [2017-08-02].

[9] Li Ming, Cheng Daopin, Hu Xintian. Design and Innovation of Tourism Products in the Age of Experience Economy-Case Study of Hexigten Banner of Inner Mongolia, Market Modernization, 2006, (16):289. [2017-08-02].

[10]Chen Xiu. Exploration and Analysis of Tourism Product Design of Eastern Henan Plain in the Age of Experience Economy-Case Study of the First Batch of Pilot Counties of Tourism Standardization Nationwide, Modern Economic Information, 2011, (11):248-249. [2017-08-02]. 